\title{
The Change of the Auricular Shape after Middle Ear Surgery Via Retroauricular Approach; Is the Reconstruction of Posterior Auricular Muscle Effective?
}

\author{
Jin Hyun Seo ${ }^{1}$, Ho Joong Lee ${ }^{1}$, Seong Ki Ahn ${ }^{1,3}$, and Dong Gu Hur ${ }^{1,2,3}$ \\ ${ }^{1}$ Department of Otorhinolaryngology, School of Medicine, Gyeongsang National University, Jinju; and \\ ${ }^{2}$ Department of Otorhinolaryngology, Changwon Gyeongsang National University Hospital, Changwon; and \\ ${ }^{3}$ Institute of Health Sciences, Gyeongsang National University, Jinju, Korea
}

\author{
중이 수술 중 후이개 접근법과 이개 모양의 변화; 후이개근의 재건은 효과적인가? \\ 서진현 ${ }^{1} \cdot$ 이호중 ${ }^{1} \cdot$ 안성기 $^{1,3} \cdot$ 허동구 $^{1,2,3}$ \\ 경상대학교 의학전문대학원 이비인후과학교실, ${ }^{1}$ 창원경상대학교병원 이비인후과, ${ }^{2}$ 경상대학교 건강과학연구원 ${ }^{3}$
}

\footnotetext{
Received February 14, 2017

Revised May 22, 2017

Accepted May 27, 2017

Address for correspondence

Dong Gu Hur, MD, PhD

Department of Otorhinolaryngology,

Changwon Gyeongsang National

University Hospital,

11 Samjeongja-ro, Seongsan-gu,

Changwon 51472, Korea

Tel $+82-55-750-8178$

Fax $+82-55-759-0613$

E-mail mdhur@hanmail.net
}

Background and Objectives Many patients experience middle ear surgery via retroauricular approach. While not a main interest of the surgery, the change of the auricular shape after surgery has been a subject of complaint by some patients. In this study, we wanted to determine if a change in the auricular shape occurs after middle ear surgery and evaluate the possibility of using reconstruction of posterior auricular muscle as a treatment option for this kind of change. Subjects and Method Forth patients who received middle ear surgery were enrolled in this study. Retroauricular incision and canal up mastoidectomy were carried out to all patients. The patients were separated into two groups randomly before surgery: one group that had the reconstruction of posterior auricular muscle during surgery, and the other that did not. The average of heights of the helix was compared. Also, patients were asked to fill out a questionnaire about auricular shape before and after surgery.

Results The heights of helix increased about $1.6 \mathrm{~mm}$ after surgery; however, the difference of increment as a result of reconstruction of posterior auricular muscle was not statistically significant. Questionnaire about the change of auricular shape after surgery showed that only $8 \%$ patients had noticed about the change of auricular shape after surgery.

Conclusion Most patients have no complaint about auricular shape after middle ear surgery via retroauricular approach. The average of heights of the helix increases after middle ear surgery. However, the reconstruction of the posterior auricular muscle is not effective for reducing the observed increment of heights of the helix following middle ear surgery via retroauricular approach.

Korean J Otorhinolaryngol-Head Neck Surg 2017;60(9):437-40

Key Words Ear auricle · Middle ear · Shape · Surgery.

\section{서 론}

만성 중이염, 고막천공 등에 대해 수술을 할 때, 중이강과

This is an Open Access article distributed under the terms of the Creative Commons Attribution Non-Commercial License (http://creativecommons.org/licenses/by-nc/4.0) which permits unrestricted non-commercial use, distribution, and reproduction in any medium, provided the original work is properly cited.
유양동에 이르기 위해 후이개 접근법이 종종 사용된다. 후이 개 접근법을 통하면 좁은 외이도를 우회하여 중이강에 이르 는 시야를 넓힐 수 있고, 유양동에 바로 접근할 수 있다. 또한 이개 뒤 모발선의 앞쪽으로 술 후 상처가 생기므로 잘 드러 나지 않는 장점도 있다. 그러나 이 접근법을 이용하여 수술을 받은 일부 환자들이 수술 후 이개 모양이 변했다고 호소하는 
경우를 종종 보게 된다. 특히 이개가 앞으로 더 두드러지는, 다시 말해 이개와 유양동 간의 거리가 멀어지는 것 같다고 말 한다. 중이염 수술에서 그 결과는 염증의 재발 여부, 청력 개 선 등에 중점을 두기 때문에 이러한 미용적 요소는 간과될 수 있다. 한편, 후이개근은 유양돌기에서 기원하여 이개 연골 뒤쪽에 붙는다. 안면신경의 후이개 분지가 지배하며 이개를 뒤로 잡아당기는 역할을 하나 실제 수의적으로 움직이지는 않는 경우가 많다. 후이개 접근법에서 이 근육은 항상 절개된 다. 본 연구는 실측과 설문을 통해 후이개 접근법을 통한 수 술 후 이개 모양의 변화가 나타나는지를 확인하고, 후이개근 의 재건이 이에 영향이 미칠 수 있는지를 확인하고 하였다.

\section{대상 및 방법}

후이개 접근법을 통해 폐쇄동 유양돌기 절제술과 고실성형 술을 받은 49명의 환자를 대상으로 전향적으로 무작위 일측 맹검 연구를 시행하였다(Fig. 1). 2015년 4월부터 순차적으로 수술한 환자를 모두 포함하였다. 수술은 한 명의 술자에 의해 동일한 방법으로 진행되었다. 피부 절개는 후이개 주름의 1 $\mathrm{cm}$ 후방에, 이개의 가장 높은 곳에서 유양돌기까지 C자 형태 로 시행하였다. 술 전에 미리 임의로 정해진 방법을 통해 환자 를 두 군으로 구분하였다. 한 군은 절개한 후이개근을 수술 종료 시 그대로 두었고, 다른 한 군은 4-0 Monosyn ${ }^{\circledR}$ (B. Braun, Melsungen, Germany)을 이용하여 재건해 주었다. 모든 환자 에서 근막과 피하 조직을 4-0 Monosyn ${ }^{\circledR}$ 으로, 피부는 4-0 $\operatorname{Nylon}^{\circledR}$ 으로 층층이 봉합하였다. 수술 전과 수술 후 1 개월, 3 개월 째 이개의 높이를 측정하였다. 이개의 높이는 이전 연구 ${ }^{1)}$ 에서 저술된 바대로 이륜과 유양돌기 사이의 거리를 3곳에 서 측정하여 평균치를 구하였다(Fig. 2). 첫 번째는 대이륜의 가장 높은 곳, 두 번째는 이륜의 뒤쪽으로 가장 바깥, 세 번 째는 이개강의 가장 아래 위치와 평행한 이륜 위치이다. 모든 환자를 대상으로 귀 모양의 변화에 대해 설문을 시행하였다.

Table 1. Questionnaire about auricular shape after surgery

Q1. Is there any change of your auricular shape after surgery?

1) None

2) Mild but tolerable

3) Moderate

4) Moderate to severe

5) Severe

Q2. Is your auricular shape unnatural after surgery?

1) None

2) Mild but tolerable

3) Moderate

4) Moderate to severe

5) Severe
설문은 추적관찰 종료시점에 시행하였으며 수술 후 이개 모 양에 변화가 있는 것 같은지와 이개 모양이 부자연스럽다고 느 끼는 지에 대해 5 단계로 응답을 유도하였다(Table 1). SPSS 12.0(SPSS Inc., Chicago, IL, USA)을 이용하여 통계적 분석 을 시행하였다. 각각의 증례에 대해 수술 전과 수술 후 이개 의 높이에 변화가 있는지 알아보기 위해 paired t-test를 시행 하였고, 두 군 간의 이개 높이 증가분에 차이가 있는지 알아보 기 위해 Mann-Whitney test를 시행하였다. $p$-value $<0.05$ 인 경우 통계적인 의미가 있는 것으로 해석하였다.

또한 수술 후 1 년 이상 추적관찰이 가능했던 19명의 환자 들에게 이개 모양에 변화가 있다고 느끼는지에 대한 전화설 문을 시행하였다.

본 연구는 참여자들의 윤리적인 보호를 위해 경상대학교병 원 기관연구윤리심의위원회의 승인을 받았으며 참여하는 대 상자들에게 연구 동의를 얻었다(2012-04-010).

\section{결 과}

총 49 명의 환자 중 후이개근을 재건한 경우가 24 명, 재건하 지 않은 경우가 25명이었다. 수술 후 3개월째 이개 높이의 측 정이 가능했던 환자는 각 군당 10 명씩이었다(Fig. 1). 대상 환 자는 남자 22명, 여자 27명이고 평균 나이는 48.2세였다. 수술 전 두 군 간의 평균 나이, 이개 높이의 차이는 없었다. 성별의 경우 후이개근을 재건하지 않은 군에 여성이 상대적으로 많 았다(Table 2). 수술 후 1 개월, 3 개월 째 측정한 이개의 높이

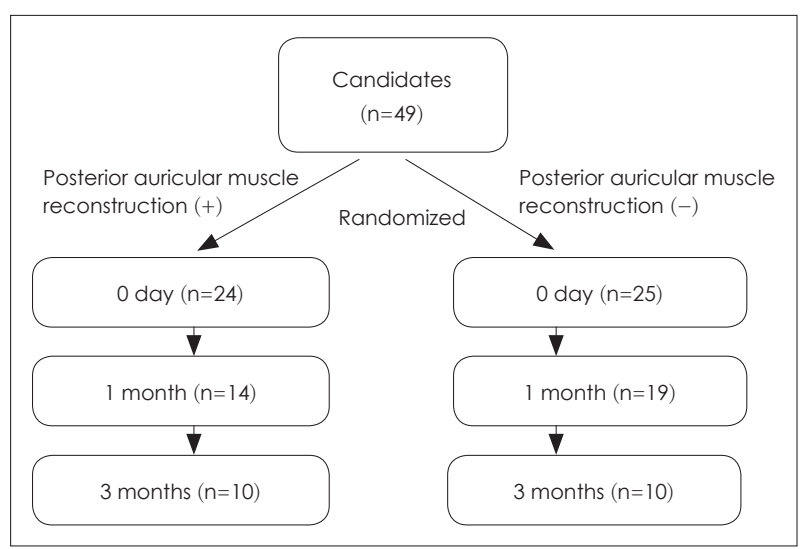

Fig. 1. Intention to treat diagram for single-blined randomized study.

Table 2. Demographic data and the width of the posterior auricular muscle

\begin{tabular}{lcc}
\hline & Reconstruction $(+)$ & Reconstruction $(-)$ \\
\hline Age (years old) & 47.5 & 48.9 \\
Sex (M:F) & $14: 10$ & $8: 17$ \\
Posterior auricular & 7 & 6.6 \\
muscle width $(\mathrm{mm})$ & & \\
\hline
\end{tabular}


Fig. 2. Measuring method of height of the helix $[X=(1+2+3) / 3]$. The point on the skull is depicted as line $A$ and passes vertically through the mastoid process.
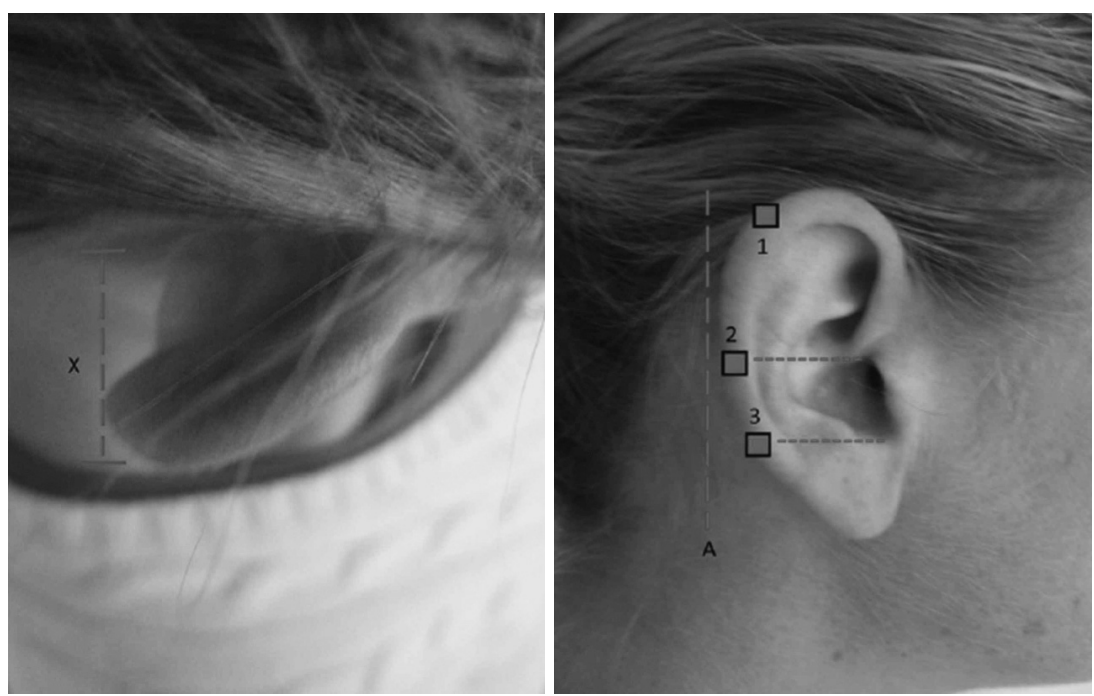



Fig. 3. The average of heights of the helix was compared between the two groups with and without the reconstruction of posterior auricular muscle. ${ }^{*} p=0.226,{ }^{\dagger} p=0.796$. D: day, M: month.

를 수술 전과 비교하였을 때 평균적으로 두 시점 모두에서 높이가 증가하는 경향을 보였다. 후이개근을 재건한 경우 수 술 후 1 개월째와 수술 전 이개의 높이를 비교했을 때 통계적 으로는 유의미한 차이가 없었으나( $p=0.059), 3$ 개월째는 유의 미한 차이를 보였다 $(p=0.038)$. 후이개근을 재건하지 않은 경 우 수술 후 1 개월째와 수술 전 이개의 높이를 비교했을 때 통 계적으로 유의미한 차이를 보였으나 $(p=0.001)$, 오히려 3개월 째는 유의미한 차이를 보이지 않았다 $(p=0.171)$. 각각의 군으 로 구분하지 않고 전체적으로 변화를 살폈을 때 수술 후 1 개월 째 $(p=0.000)$ 와 3 개월째 $(p=0.011)$ 모두에서 통계적으로 유의 하게 이개 높이가 증가하는 것을 알 수 있었다. 수술 전과 수술 후 이개의 높이 평균의 차는 1 개월째 $1.4 \pm 2.6 \mathrm{~mm}, 3$ 개월째 $1.6 \pm 2.5 \mathrm{~mm}$ 였다. 이개 높이 증가분에 대해 두 군 간의 차이 가 있는지를 살펴보았을 때 수술 후 1 개월째와 3 개월째 모두 에서 통계적으로 유의미한 차이를 보이지는 않았다(Fig. 3).
설문을 통해 분석한 결과, 술 후 이개의 모양에 변화가 있다 고 느끼거나 이개가 자연스럽지 못하다고 느낀 환자는 전체 환 자의 $8 \%(4 / 49)$ 였으며 후이개근을 재건한 군과 재건하지 않은 군에 각각 2 명씩이었다. 또한 수술 후 1년 이상 추적관찰이 가 능했던 19 명의 환자들에게 전화설문을 시행하였으며 이개 모 양에 변화가 있다고 느끼는 환자는 없었다.

\section{고 찰}

고실성형술, 유양돌기 절제술에서 후이개 접근법 시행 후 이 개의 모양 변화에 대한 연구는 많지 않다. Inwood 등에 에 의 하면 고막재건술을 받은 환자 중에서 경외이도 접근법을 시 행한 환자의 $4 \%$, 후이개 접근법을 시행한 환자의 $15 \%$ 가 이개 모양의 변형을 인지하였다. 후이개 접근법을 시행하였을 때 이개 모양의 변화가 더 있을 수 있다는 결론이다. Coskun 등구 은 20명의 환자를 대상으로 경외이도 접근법과 후이개 접근 법으로 수술한 후 이개-유양돌기각을 측정하였고, 후이개 접 근법을 시행한 경우 통계적으로 유의하게 수술 후 이개-유양 돌기각이 증가함을 보고하였다. 이는 후이개 접근법에서 상 피층, 피하층, 골막, 그리고 후이개근이 절개되기 때문이며 이 후 봉합을 하더라도 이개를 지지하지 못할 정도로 약화된다 고 설명한다. 하지만 두 연구 모두에서 수술 후 이개 변형에 대해 문제를 제기하는 환자는 없었다고 한다.

본 연구에서도 후이개 접근법을 시행할 경우 수술 후 이개 의 높이가 높아짐을 확인할 수 있었다. 하지만 그 정도가 평 균 $2 \mathrm{~mm}$ 이내로 크지 않았으며 오직 전체 환자의 $8 \%$ 에서만 이개의 모양의 변화를 인지하였고 이를 문제 삼는 환자는 없 었다.

연구자는 이전의 연구에서 이개를 지지하는 구조물로 언급 
된 후이개근이 이개를 뒤로 당기는 역할을 하기 때문에 이 근 육을 재건할 경우 이개 높이의 변화를 줄일 수 있지 않을까라 는 생각을 하였다. 하지만 후이개근을 재건하여도 술 후 이개 의 높이가 변화하는 것을 방지할 수는 없었다. 이는 앞서 언 급된 바와 같이 후이개근뿐만 아니라 근막, 피하층, 피부의 연 속성 등이 이개를 지지하는 데 함께 역할을 하기 때문으로 생 각된다.

본 연구의 계획과정에서 성별에 따른 차이를 고려하지 않았 다. 이는 개개인에서 수술 전후 결과의 차를 비교하는 것을 계 획하고 이에 따른 결과를 분석하는 과정에서 수술 전 이개 높이의 남녀 차가 있더라도 결과에 영향을 주지는 않을 것으 로 생각했기 때문이다. 하지만 무작위 배정을 통해 결과적으 로 두 군 간의 성별 차가 발생하였고, 이는 본 연구의 제한점 으로 생각되며 향후 추가 연구를 통해 보완이 필요하다.

이전 연구 결과와 본 연구의 결과를 종합하면 후이개 접근 법을 시행할 때 이개 모양의 변화가 나타날 수 있으나 그 정도 가 크지 않다. 따라서 후이개 접근법을 통해 수술을 시행할
때 사전에 환자에게 이개 모양의 변화 가능성에 대해 설명한 다면 수술 후 문제가 되는 경우는 없을 것으로 생각된다. 그럼 에도 불구하고 수술 후 이개 모양의 변화를 최소화하기 위해 절개와 역순으로 꼼꼼히 봉합을 시행하는 것에 주의를 기울여 야 할 것이다.

후이개 접근법을 통한 수술에서 수술 후 이개 높이의 변화 가 일부 관찰될 수 있으며, 환자가 주관적으로 변화를 느끼는 비율은 $10 \%$ 전후이다. 후이개근을 재건한다고 하여도 이개 높 이의 변화를 예방하지는 못한다.

\section{REFERENCES}

1) Mashhadi S, Butler DP. A strategy for assessing otoplasty outcome intra-operatively. J Plast Reconstr Aesthet Surg 2012;65(7):984-5.

2) Inwood JL, Wallace HC, Clarke SE. Endaural or postaural incision for myringoplasty: does it make a difference to the patient? Clin Otolaryngol Allied Sci 2003;28(5):396-8.

3) Coskun BU, Cinar U, Seven H, Ugur S, Dadas B. The effects of the incision types in myringoplasty operations on cosmesis. Eur Arch Otorhinolaryngol 2006;263(9):820-2. 